\title{
Analysis of the relationship between daylight illuminance and cognitive, affective and physiological changes in visual display terminal workers
}

Building Serv. Eng. Res. Technol. $0(0) 1-16$

(C) The Author(s) 2019

Article reuse guidelines: sagepub.com/journals-permissions DOI: I0.I I77/0I436244|989444 I journals.sagepub.com/home/bse

@SAGE

\author{
M Öner ${ }^{1,2} \mathbb{D}$, T Kazanasmaz², F Leccese' and \\ G Salvadori' ${ }^{1}$ (D)
}

\begin{abstract}
This study explored the impact of daylight illuminance on cognitive load during visual display terminal use by means of various physiological, performance and subjective measures. Repeated-measures design was adopted to identify the impact of variations in daylight levels that were manipulated through the shading system configurations (shading-on; shading-off). A total of 30 subjects performed visual and cognitive demanding tests. Performance measures were supported by subjective data and eye-related measures during the experimental analysis. Results revealed that the use of a shading system had positive impact on sustained attention. Concerning ocular measures, percentage of eye closure values showed opposite tendencies among vigilance and sustained attention demanding tests. Eye aspect ratio-max and blink duration were significantly correlated with reported glare sensation. In all tests, eye aspect ratio-max was found significantly higher in lower illuminances. Search velocity was significantly correlated with ocular variables in higher illuminances whereas sustained attention showed an opposite trend. This, initially, explains that even slight differences in daylight illuminance might have distinctive effects on the relationship between different groups of assessment variables while measuring cognitive load. Secondly, it proves the significance of carrying out sensitive experiments in terms of both light levels and test characteristics.

Practical application: The findings of this study could suggest that a practical application, the use of a shading device, might deliver an efficient solution on such a multifaceted question about the potential effects of luminous environment on the evaluation of cognitive load. Work environments might be considered as cognitively efficient if only the harmony of less mental effort, more satisfaction and less health problems exist, which together ultimately deliver higher work performance. In real-world work environments, application of such shading devices involves advantages not only for avoiding excessive daylight exposure or optimizing energy consumption, but also facilitating cognitive, affective and physiological processes of individuals.
\end{abstract}

\footnotetext{
'School of Engineering, University of Pisa, Pisa, Italy

${ }^{2}$ Department of Architecture, İzmir Institute of Technology, Urla-İzmir, Turkey
}

\section{Corresponding author:}

M Öner, University of Pisa, Largo Lucio Lazzarino 2, Pisa 56100, Italy.

Email: m.oner@studenti.unipi.it 


\section{Keywords}

Daylight, luminous environment, cognitive performance, cognitive load, ocular behaviour, visual display terminal

\section{Introduction}

The visual display terminal (VDT) has recently been the most convenient tool in human-computer interaction, particularly in office environments. ${ }^{1-3}$ While working with VDTs, many cognitively demanding tasks are performed by individuals. ${ }^{4}$ These tasks may require several cognitive functions such as mental workload, decision-making, sustained attention and stimuli interpretation, that potentially lead to a higher degree of cognitive load. The term of cognitive load is basically the level of measurable mental effort exerted by an individual in response to one or more cognitive tasks. However, determination and interpretation of cognitive load is still challenging due to its multidimensional character. So far, several models have been proposed and used to measure cognitive load. Of those, Paas and Van Merriënboer ${ }^{5}$ constructed a model suggesting that the possible causal factors of the cognitive load were referred to characteristics of the task, to characteristics of the subject performing the task, or to interactions between both. It was then modified by Choi et al. ${ }^{6}$ based on the recent research revealing the role of physical environment characteristics on cognitive performance. Here physical learning environment was considered as a potential causal factor which refers to the entire range of physical attributes of a space where the activities take place. Also, it is this model that was taken into consideration in the current study.

According to the assumptions used in the model of Choi et al., ${ }^{6}$ the assessment factors are based on the dimensions of mental load, mental effort and performance, which are still be discussed in the literature for involving a variety of investigation techniques. ${ }^{7}$ Although there is not a standardized one, these techniques may be divided into three groups: (i) subjective measures, i.e., the NASA task load index; ${ }^{8}$ (ii) various physiological measures, i.e., EEG, ${ }^{9}$ heart rate ${ }^{10}$ or eye activity, ${ }^{1-13}$ and (iii) a wide range of performance measures, i.e. memory, ${ }^{14}$ time spent on a test ${ }^{15,16}$ or error rates (ERs). ${ }^{17}$

Until now, limited research pertaining to the effects of physical learning environment on cognitive processes have been carried out, despite the fact that the physical attributes of a place involve sensory stimuli that is perceived by human senses in different forms such as vision, temperature, smell or hearing. Such sensory stimulations may in fact simply improve or diminish cognitive functions via physiological, psychological or physical paths. Physical characteristics of a built environment, that are, lighting conditions, acoustics, thermal conditions and air quality, accordingly have an impact on the cognitive load and learning capacity of an individual. Of those, luminous environment was often treated as a control variable and kept constant throughout the experiments. ${ }^{6}$

Several studies, on the other hand, have revealed that the illuminance values, ${ }^{18-21}$ luminance distribution, ${ }^{22,23}$ types of artificial light sources, ${ }^{24,25}$ colour temperature ${ }^{18,26}$ have an effect on cognitive performance. However, these studies were predominantly conducted in static artificially lit environments and only a few attempted to examine cognitive performance under daylight illumination which has varying light output. ${ }^{27,28}$ While their valuable contribution to the literature cannot be ruled out, there as yet exists only little research on the impact of natural light on cognitive processes in specifically VDT work environments. In support of this lack, this article was undertaken to test 
the cognitive, physiological and affective changes under two realistic office lighting settings. Previous studies have proved that daylight is the most preferred light source in working spaces $^{29}$ for being more efficient in physical, visual, and psychological health. ${ }^{30-32}$ Taking the task difficulty and the individuals' cognitive demands into consideration, a well-conceived lighting design is required for preventing or reducing visual discomfort and therefore increasing workplace satisfaction and stimulating cognitive functions. ${ }^{33,34}$ Hence, this article focused exclusively on daylight as the source of illumination and investigated its cognitive, affective and physiological effects on VDT workers in response to changing daylighting conditions. The main goal of the current research was to analyse relationships between the luminous environment, performance and learning. Also, the influence of the luminous environment on cognitive functions from an affective or a physiological standpoint was investigated in order to find out whether the daylighting design choices can have positive effects on cognitive functions.

\section{Materials and methods}

\section{Subjects}

A total of 30 healthy ( 23 male and 7 female) undergraduate and postgraduate students with an age ranging from 20 to 30 years $(M=24.6$, $\mathrm{SD}=3.42$ ) participated in the study. Two days before the experimental session, they were asked to keep their sleep-wake schedule as similar as possible to their sleep routine on workdays ( $\pm 30 \mathrm{~min})$ as stated in Munich Chronotype Questionnaire. ${ }^{35}$ In this way, the possibility of confounding factors associated with general fatigue that possibly causes irregular eye dynamics, and consequently may be confused with the expected influence of different illuminance levels during the experiment would be eliminated as much as possible. All subjects had normal (visual acuity $>0.8$ ) or corrected sight without any colour blindness (vision test;

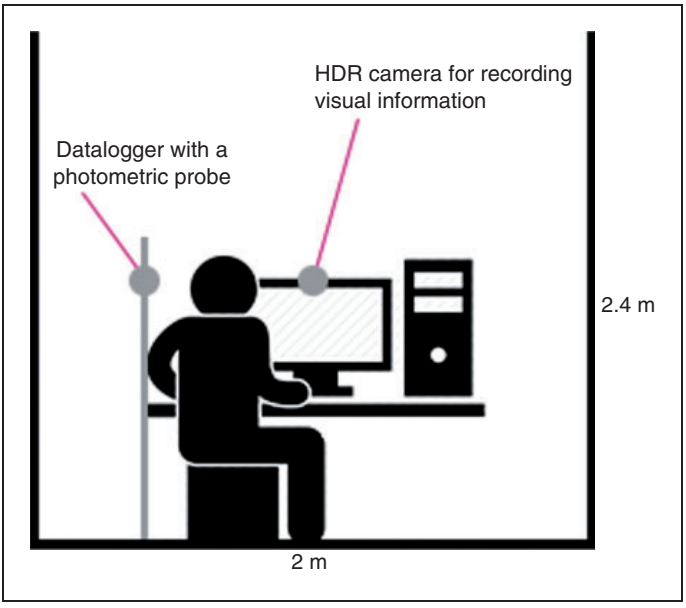

Figure I. Schematic view of the mock-up laboratory setting.

www.essilor.com). People between 20 and 30 years old have the similar light sensitivity because of the aging effect on the eyes as stated in a validated light sensitivity test by Fortuin. ${ }^{36}$ For this reason, sampling of subjects was applied to select subjects only who were within this age range and were using a computer at least $8 \mathrm{~h}$ every day. To avoid post-lunch drowsiness during the afternoon sessions, the subjects were requested to have lunch at least $1 \mathrm{~h}$ prior to the experiment. Finally, the scope of the study and the expected outcomes of the experiment were not explained to the subjects.

\section{Experimental setup and procedure}

The experiments took place in a full-scale mockup VDT workstation of $2 \mathrm{~m} \times 2 \mathrm{~m} \times 2.4 \mathrm{~m}$, located on top of a two-story building at the Lighting and Acoustics Laboratory of the University of Pisa (see Figure 1). The mock-up was side-lit by $115^{\circ}$ southeast-oriented façade windows consisting of double glass with a light transmission of $80 \%$. With the operation of an heating, ventilation, and air conditioning system, the room temperature of $20-24^{\circ} \mathrm{C}$ and relative humidity of $20-60 \%$ were kept steady and similar over the time of the experiments, 
according to the OSHA guidelines on office indoor air quality. ${ }^{37}$

In each experiment, the subject's visual field included the identical views consisting of a workstation and a curtain fabric covering for the sides and the ceiling. The desk was placed parallel to the windows and the subjects faced the glazing at a distance of about $1 \mathrm{~m}$. Although this sort of workplace setup is not highly recommended, the justification for doing so is that the impacts of changing daylighting conditions were considered to be most distinct in the subjects' cognitive, affective and physiological processes.

The features of the mock-up workstation and the furnishings are described in detail in our previous article. ${ }^{38}$ The subjects were able to freely change their own sitting height provided that the viewing distance of $60 \mathrm{~cm}$ was kept in a constant position. The layout of the workstation was kept identical throughout the whole experiment. Surface properties were chosen in such a way that the risks of veiling reflections, annoying brightness, etc. would be minimized in order to avoid potential perceptual distractions due to the luminance distribution surrounding the screen. ${ }^{1}$ The room surfaces were measured by using the photo-radiometer Delta Ohm HD2102.1 and had reflectance properties of: $p_{\text {curtain }}=0.06, p_{\text {table }}=0.14, p_{\text {floor }}=0.28$.

\section{Experimental equipment}

Visual information was recorded with a Canon EOS $500 \mathrm{D}$ camera which was placed right above the computer screen in such a way that focused on the eyes of the subjects, and photometric measurements were carried out throughout the sessions by using a Delta Ohm datalogger HD2101.1 with the photometric probe LP 471 PHOT which was properly calibrated and normalized prior to the study (calibration uncertainty lower than $4 \%$ ).

\section{Image processing}

Ocular information of the subjects was extracted with the application of Python, ${ }^{39}$ which is a

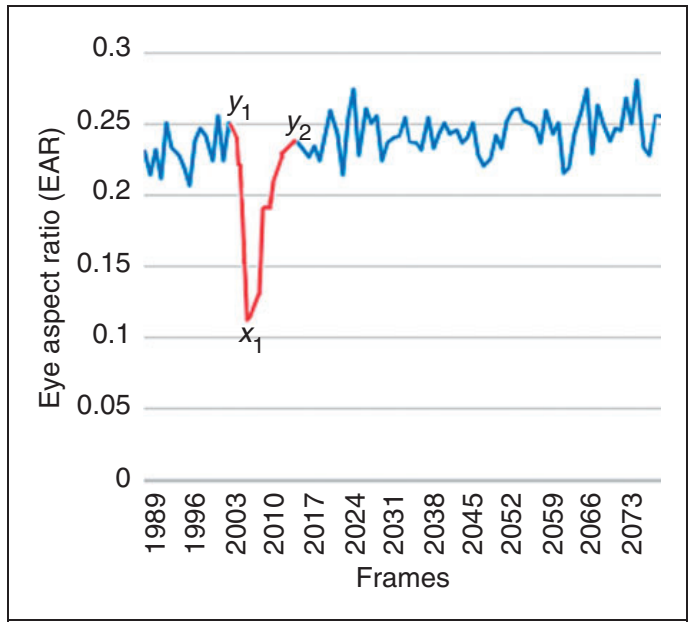

Figure 2. Example of the blink detection. The eye aspect ratio (EAR) is automatically calculated by the algorithm and the red polylines indicates the blinking action.

programming language that executes code by statement. An algorithm proposed by Soukupová and $\mathrm{Cech}^{40}$ was used for video processing. With this algorithm, video recordings of each subject are decomposed into a sequence of frame image and the eye landmarks are detected for every video frame. Finally, the eye aspect ratio (EAR) is computed based on the ratio of distances between facial landmarks of the eyes. An example of an EAR of a video sequence is shown in Figure 2. The EAR is computed automatically and the moment where the eye fully closes is indicated with $x_{1}$. Blink duration (BD) and percentage of eye closure (PERCLOS) values are calculated by dividing the total number of frames between $y_{1}$ and $y_{2}$ into 30 , because the shooting rate of the camera is 30 frames/s. The detailed definitions of ocular parameters are further given in subsection 'Dependent measures'.

\section{Stimuli}

Two configurations (shading-on; shading-off) were selected to determine the effect of a solar shading strategy on performance. Artificial light 
sources were turned off and the room relied only upon daylight during the experiments. Vertical illuminance at the eye level $\left(E_{\mathrm{V}}\right)$ was recorded every $5 \mathrm{~s}$. Two types of analyses were performed to explore the statistical difference between two configurations. First, data distribution was tested for normality (Kolmogorov-Smirnov test), which revealed that the data for shadingon setting was not normally distributed ( $p=0.020)$ while the data for shading-off setting had normal distribution $(p=0.200)$. Hence, non-parametric analogue of the paired $t$-test, Wilcoxon signed-rank test was used to explore the difference on $E_{\mathrm{V}}$ between two groups. The result ( $p=0.00008, Z=-4.453)$ revealed a significant difference between two groups, hence we named our new independent scenarios as ' $E_{\mathrm{V}}$-low' and ' $E_{\mathrm{V}}$-high' to be referred hereafter in the following sections of this article. Descriptive statistics for light levels of each configuration are also listed in Table 1.

\section{Study design}

The data was acquired in two time periods in which the experiments were performed between 10:00 a.m. and 12:00 a.m. or 03:00 p.m. and 05:00 p.m. for a period of three weeks in 2018 (from 8 May to 11 June) and for a period of four weeks in 2019 (from 15 April to 13 May). Although the experiments took place during spring and summer, a large variability in the external sky conditions necessarily caused overlaps between $\mathrm{E}_{\mathrm{v}}$-low and $\mathrm{E}_{\mathrm{v}}$-high groups (see Table 1). Time periods and associated sky conditions of the experiment days are also given in Figure 3, which give concrete clues regarding the illuminance variations.

A within-subject repeated-measures design was employed, which requires each subject to perform the test twice during the experiment for each solar shading position: (i) where the shading system was completely inactivated and (ii) where the slats were tilted $5^{\circ}$ downward to the exterior of the experimental space (see Figure 4).
Table I. Descriptive statistics for the independent variables.

\begin{tabular}{lllll}
\hline Solar shading strategy & $\begin{array}{l}E_{\vee} \\
(\text { Mean })\end{array}$ & $\begin{array}{l}E_{\vee} \\
(S D)\end{array}$ & $\begin{array}{l}E_{V} \\
(\text { Min })\end{array}$ & $\begin{array}{l}E_{V} \\
(\text { Max })\end{array}$ \\
\hline Shading-off (Evhigh) & 1384 & 574 & 224 & 2324 \\
Shading-on (Ev-low) & 824 & 471 & 185 & 2033 \\
\hline
\end{tabular}

To minimize any order effects, the sequence of the shading positions during sessions was randomized across subjects. Besides, short training trials were performed prior to the experimental sessions to avoid any learning effect. During the experiment, subjects performed a battery of tests aimed at measuring several cognitive functions such as search velocity (SV), vigilance and divided attention, which are of essential characteristics of regular VDT works. The order of the tests performed was kept the same in every session but the stimuli presented in each test were random (e.g., text/colour combinations in Stroop test). Besides performance measures, subjective task performance (STP) questionnaires were filled in after each test, in order to explore the subjects' performance rating on the tests. Subjective sleepiness scale (KSS) was assessed at the beginning and the end of each experimental session. The subjects were also asked to complete a glare sensation vote (GSV) scale to measure the level of perceived glare during the experiment. Overall, the experimental activity of each subject including instructions, tests, questionnaires and a short break between two sessions took approximately $1 \mathrm{~h}$ to complete. The time schedule of the activities performed during the experiment is illustrated in Figure 5.

\section{Dependent measures}

Dependent measures that were divided into three groups according to the multidimensional approach adopted ${ }^{38}$ are as follows:

(i) Performance measures (SV, vigilance, sustained attention). 


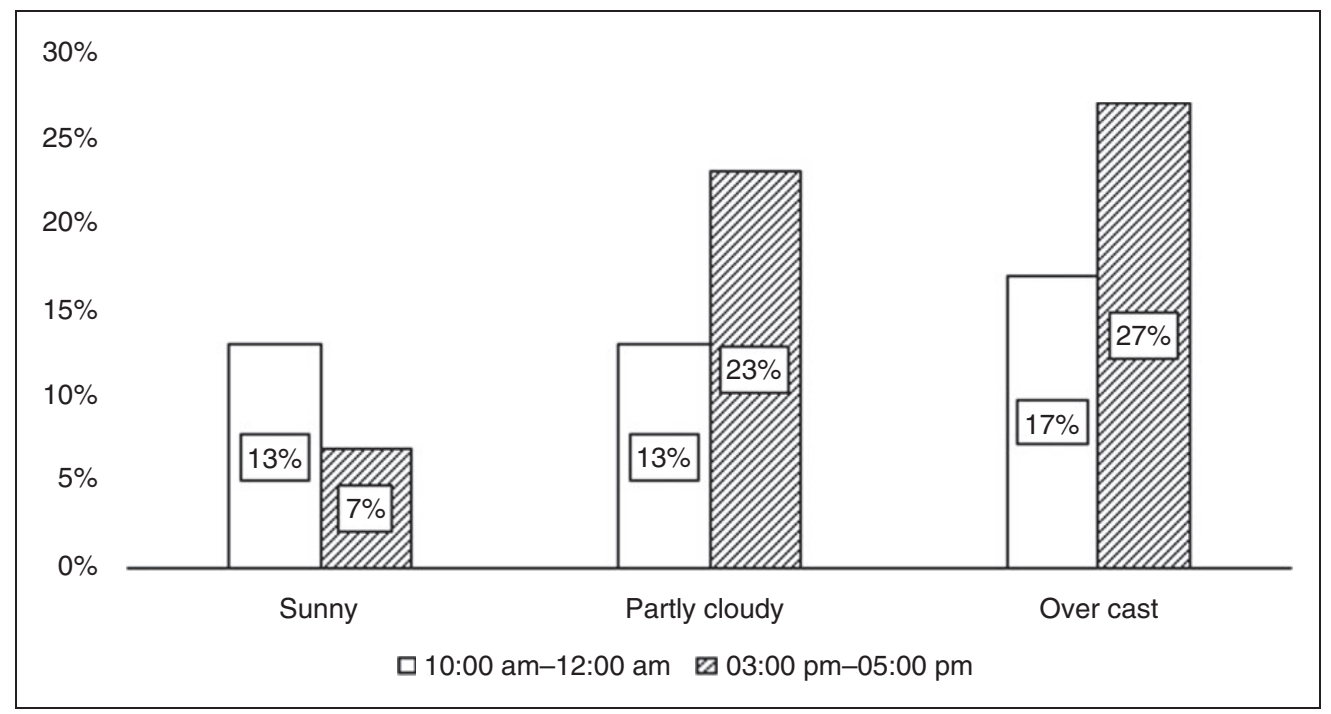

Figure 3. Time periods and associated sky conditions.

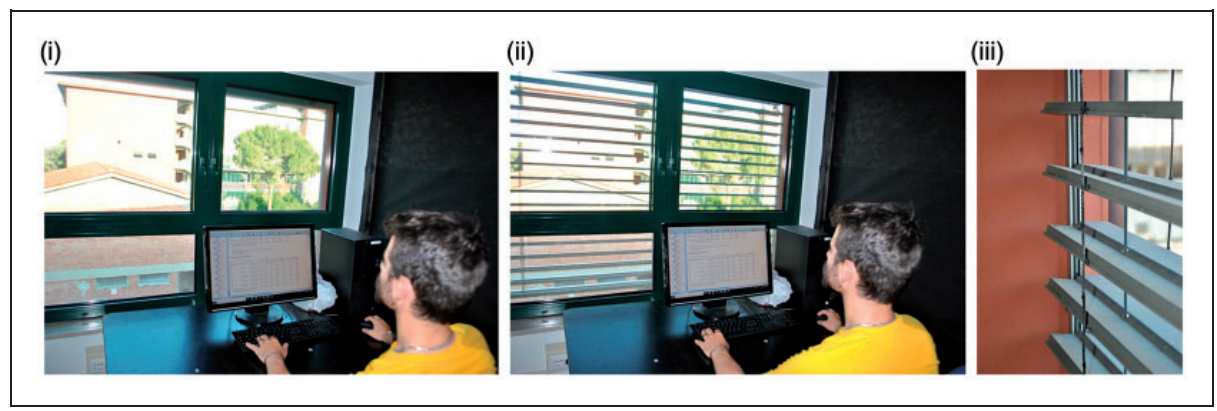

Figure 4. Position of the external solar shading where the slats were (i) inactive, (ii) tilted $5^{\circ}$ downward to the exterior and (iii) close-up view of the slats.

(ii) Ocular measures (blink rate (BR), BD, PERCLOS, EAR).

(iii) Subjective measures (subjective alertness, GSV, STP).

Regarding the group of performance indicators, a letter search test was initially administered for measuring SV. Differently from the ISO standard test procedure measuring the effectiveness of subjects' search performance to find target characters embedded in alphanumerics on screen, ${ }^{41}$ in this study, an approximately 5-min letter search test in multiple target settings was conducted to measure SV for varying levels of difficulty. ${ }^{42,43}$ The test consisted of a total of 50 search targets with 5, 10, 15, or 20 items. Average response time (RT; ms) of search displays was recorded as output measures. Vigilance performance was measured with Mackworth clock test. ${ }^{44,45}$ The test lasted approximately $5 \mathrm{~min}$ depending on the participant reaction times and the score was calculated as the sum of missed and wrongly detected skips, which was then used as an outcome variable. Sustained attention was measured with a Stroop colour-naming test that requires to name 


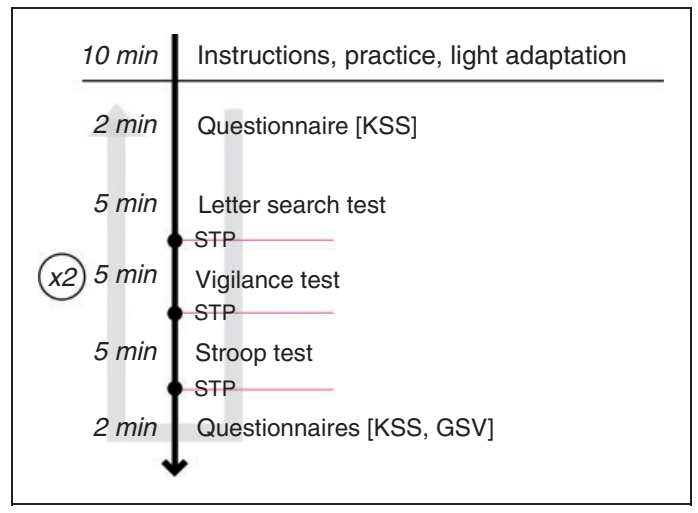

Figure 5. Time schedule of the experimental stage.

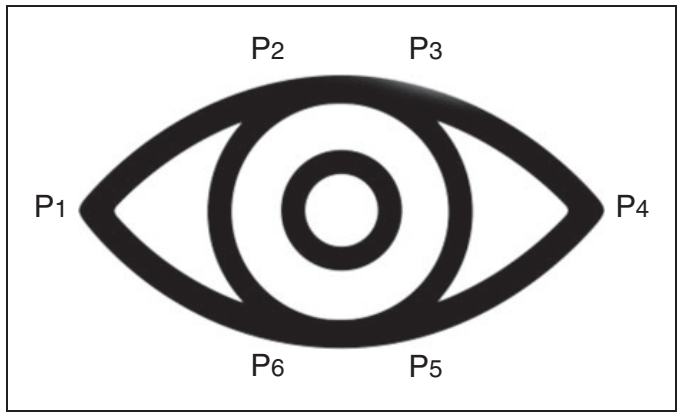

Figure 6. Locations of the automatically detected eye landmarks $\mathrm{p}_{i}$. The eye aspect ratio (EAR) is computed for every video frame by equation (I). the colour of the appeared word on screen. In this test, it takes more cognitive effort and processing time when the colour and word are incongruent (e.g., the word YELLOW is displayed in blue font colour) when compared with the effort and time spent in congruent trials (e.g., RED written in red font colour). In each session, a total of 70 trials were randomly displayed at the centre of the screen in 20-pt Arial font. ${ }^{42,43}$ Time spent on this test was approximately $5 \mathrm{~min}$ and the reaction time (RS) to congruent and incongruent stimuli was used as outcome variable.

As for the ocular measures, BR was chosen for the first variable since lower BR is associated with increases in cognitive demand. ${ }^{46}$ Decrease in $\mathrm{BR}$ is also related to visual discomfort in many studies ${ }^{47-49}$ in which ambient light levels present in the room are acknowledged to play an influential role on BR. BD was chosen as the second ocular variable. Generally, prolonged eye closure is usually associated with higher cognitive load, ${ }^{50}$ lower performance ${ }^{51}$ or more visual demand. ${ }^{52}$ PERCLOS, the third ocular variable, is the percentage of time that the eye is closed per unit of time, and that indicates slow eye closure rather than blinks. There are actually three metrics for the identification of PERCLOS which are P70, P80 and EYEMEAS(EM). Among these metrics, P80 is considered as the most reliable standard so far, in which eye is regarded as close in the case that palpebral fissure is decreased to a percentage of $20 \%$ and below. ${ }^{53}$ PERCLOS value is obtained from BD data of the subjects within unit time. Although PERCLOS defines the level of fatigue in general terms, some previous research adopted this metric to identify changes in cognitive load, ${ }^{54,55}$ as will be adopted in this study likewise. EAR is the last ocular variable in which the eye landmarks are detected for every video frame and the EAR between height and width of the eye is computed via algorithm developed by Soukupová and $\mathrm{Cech}^{40}$ (see Figure 6). In this method, the EAR values of the left and right eye are automatically averaged by the algorithm since the both eyes blink simultaneously. In the current study, we also identified $\mathrm{EAR}_{\text {min }}$ and $\mathrm{EAR}_{\text {max }}$ values differently from the approach of Soukupová and Cech. ${ }^{40}$ Additionally, in order to overcome a potential problem associated with the $\mathrm{EAR}_{\text {min }}$ values which can be as low as eye blink moments, EAR max $_{\text {was }}$ chosen as the only EAR parameter. According to our approach, a decrease in $\mathrm{EAR}_{\max }$ level is associated with higher visual discomfort. Lastly, considering that every individual's eye openness may differ, in the current study we estimated the EAR values of each subject 
individually and thus administered withinsubject designs

$$
E A R=\frac{\left\|p_{2}-p_{6}\right\|+\left\|p_{3}-p_{5}\right\|}{2\left\|p_{1}-p_{4}\right\|}
$$

Considering the subjective measures, selfreported alertness was measured with the Karolinska Sleepiness Scale (KSS). ${ }^{56}$ In each session, subjective sleepiness level was measured with a modified Italian version of KSS just prior to the letter search test and just after the Stroop test. The sensation of glare experienced by the subjects was measured with GSV, which was developed by Hopkinson. ${ }^{57}$ This measurement employs a 4-point scale with response options from 1 (imperceptible) to 4 (intolerable). In this study, subjective sensation of visual discomfort was examined at the end of each experimental session by using GSV scale. Finally, subjective evaluation of cognitive efficiency was assessed at the end of each test with a visual analogue scale adopted from Huiberts et al. ${ }^{58}$ The original English version of STP was translated into Italian in this study. It consisted of four questions with response options on a scale from 0 (not at all) to 100 (very much) where subjects rated their subjective experience of a task: (i) overall success - how well subjects thought they had performed on the task; (ii) motivation - how motivated they were to perform the task as well as possible; (iii) concentration - how well they could concentrate on the task; (iv) mental effort - how much mental effort they had to put into the task. The Cronbach's alpha reliability measure for all items was between $\alpha=.73$ and $\alpha=.78$, with an acceptable internal consistency.

\section{Statistical analyses}

All the statistical analyses were conducted using IBM SPSS statistics software version 22. Prior to the data analysis, each variable was verified for normality with Kolmogorov-Smirnov test. Results of the cases including SV and vigilance performances showed a violation of normality $(p<0.05)$. In addition, the Levene's tests of homogeneity were carried out to identify any significant differences between variances of variables. Results of the tests indicated that the only significant violation was found in vigilance performance data $(p<0.05)$. Based on the results of the normality and homogeneity tests, parametric tests were applied to normal data $(p>0.05)$ and non-parametric tests were applied to non-normally distributed data $(p<0.05)$. A significance level of $p=0.05$ was considered to denote statistical significance throughout the study. In general, data analysis consisted of three parts.

Firstly, a paired $t$ test was used to investigate whether any effect of daylight variations $\left(E_{\mathrm{V}^{-}}\right.$ low and $E_{\mathrm{V}}$-high) on performance, physiological and subjective variables could be found, and if so, to identify in which direction.

Secondly, the relationship between the physiological and performance measures was investigated separately under $E_{\mathrm{V}}$-low and $E_{\mathrm{V}}$-high conditions and task-dependent. In doing so, daylighting conditions that manipulated the strengths of the relationships between physiological and cognitive performance measures were highlighted, and the more effective setting for stronger relationships was drawn out.

The final part was to investigate whether any relationship exists between the subjective measures and the performance measures, to check changing daylighting conditions had affective effects on cognitive performance of individuals.

\section{Results}

\section{Comparisons of ocular parameters between different luminous environments}

The pairwise comparisons showed that the EAR $_{\max }$ was significantly higher under low levels of vertical illuminance in letter search test $(t=-3.604 ; d f=29 ; p<0.01)$, vigilance test $(t=-2.269 ; d f=29 ; p<0.05)$ and Stroop test $(t=-3.211 ; \quad d f=29 ; \quad p<0.01)$. PERCLOS values showed opposite tendencies among vigilance and Stroop tests. PERCLOS 
Table 2. Results from the paired $t$ tests of ocular variables with the main effect of daylighting condition.

\begin{tabular}{|c|c|c|c|c|c|}
\hline \multirow[b]{2}{*}{ Dependent ocular variables } & \multirow{2}{*}{$\frac{E_{\vee} \text { high }}{\text { Mean }}$} & \multirow{2}{*}{$\frac{E_{\vee} \text { low }}{\text { Mean }}$} & \multirow[b]{2}{*}{$t$} & \multirow[b]{2}{*}{$d f$} & \multirow[b]{2}{*}{$p$} \\
\hline & & & & & \\
\hline $\mathrm{BR}$ - letter search test & 0.28447 & 0.29277 & -0.574 & 29 & 0.570 \\
\hline $\mathrm{BR}$ - vigilance test & 0.22163 & 0.22037 & 0.055 & 29 & 0.956 \\
\hline BR - Stroop test & 0.21907 & 0.21753 & 0.083 & 29 & 0.935 \\
\hline $\mathrm{BD}(\mathrm{ms})$ - letter search test & 376.0360 & 367.1317 & 1.005 & 29 & 0.323 \\
\hline $\mathrm{BD}(\mathrm{ms})$ - vigilance test & 377.8383 & 365.9727 & 1.849 & 29 & 0.075 \\
\hline BD (ms) - Stroop test & 335.8183 & 319.3147 & 2.539 & 29 & 0.017 \\
\hline PERCLOS - letter search test & 9.7493 & 10.9670 & -1.330 & 29 & 0.194 \\
\hline PERCLOS - vigilance test & 7.6877 & 5.7807 & 2.644 & 29 & 0.013 \\
\hline PERCLOS - Stroop test & 7.2967 & 8.5327 & -2.399 & 29 & 0.023 \\
\hline $\mathrm{EAR}_{\max }$ - letter search test & 0.333640 & 0.357097 & -3.604 & 29 & 0.001 \\
\hline $\mathrm{EAR}_{\max }$ - vigilance test & 0.339817 & 0.357707 & -2.269 & 29 & 0.031 \\
\hline $\mathrm{EAR}_{\max }-$ Stroop test & 0.339463 & 0.355427 & -3.211 & 29 & 0.003 \\
\hline
\end{tabular}

BR: blink rate; $B D$ : blink duration; PERCLOS: percentage of eye closure; EAR $_{\text {max: }}$ eye aspect ratio-max.

Differences are significant at $p<0.05$ level.

was significantly lower in $\mathrm{E}_{\mathrm{V}}$-low scenario than in $\mathrm{E}_{\mathrm{V}}$-high during vigilance test $(t=2.644$; $d f=29 ; p<0.05)$, whereas significantly higher PERCLOS was found in Stroop test under low levels of vertical illuminance $(t=2.644 ; d f=29$; $p<0.05)$. No statistically significant difference was found on PERCLOS value in letter search test across $\mathrm{E}_{\mathrm{V}}$-low and $\mathrm{E}_{\mathrm{V}}$-high scenarios $(t=-2.399 ; \quad d f=29 ; \quad p<0.05)$. Finally, no effect of shading was found on BR in any of the tests but it does affect BD significantly $(t=2.539 ; d f=29 ; p<0.05)$. Table 2 lists the $p$ values for the main effect of daylighting condition on ocular variables.

\section{Comparisons of performance parameters between different luminous environments}

As for the letter search, vigilance and sustained attention tests, outcome performance variables were specified as SV, ER and RT, respectively. Table 3 shows the detailed information on each relationship in $\mathrm{E}_{\mathrm{V}}$-high and $\mathrm{E}_{\mathrm{V}}$-low settings. From the data, a significant difference was observed only in RT of congruent trials during sustained attention test, showing faster $\mathrm{RT}$ in $\mathrm{E}_{\mathrm{V}}$-low setting $(t=2.283 ; \quad d f=29$; $p<0.05)$.
The relationships between ocular parameters and performance indicators

The analyses of the relationship between the ocular parameters and the cognitive performance indicators were performed separately under $\mathrm{E}_{\mathrm{V}}$-low and $\mathrm{E}_{\mathrm{V}}$-high settings. In $\mathrm{E}_{\mathrm{V}}$-high setting, the performance parameter 'search velocity' was found to be significantly correlated with $\mathrm{BD}$ and $\mathrm{EAR}_{\max }(r=-0.362, p=0.049)$, indicating that the maximum level of EAR increases as the average time spent on search test increases (see Table 4).

As for the $\mathrm{E}_{\mathrm{V}}$-low setting, $\mathrm{BR}$ was significantly correlated with RT in congruent $(r=0.366$, $p=0.047)$ and $\mathrm{RT}$ in incongruent trials $(r=0.374, p=0.042)$, revealing that increased frequencies of eye blinks were in line with the reduced speed on reaction time. PERCLOS was also found positively correlated with RT in congruent $(r=0.368, p=0.045)$ and $\mathrm{RT}$ in incongruent trials $(r=0.368, p=0.046)$, see Table 5 .

\section{The relationships between subjective and objective performance indicators}

Mental effort was found to be significantly correlated with the errors made during the 
Table 3. Within-subject cognitive performance comparisons in EV-high and EV-low scenarios.

\begin{tabular}{|c|c|c|c|c|c|c|c|}
\hline \multirow[b]{2}{*}{ Performance variables } & \multicolumn{2}{|l|}{$E_{\vee}$ high } & \multicolumn{2}{|l|}{ Evlow } & \multirow[b]{2}{*}{$t$} & \multirow[b]{2}{*}{$d f$} & \multirow[b]{2}{*}{$p$} \\
\hline & Mean (SD) & SD & Mean & SD & & & \\
\hline $\mathrm{SV}(\mathrm{ms})$ & 1001.29 & 172.12 & 1030.29 & 343.35 & -0.448 & 29 & 0.658 \\
\hline VI (error rate) & 4.23 & 4.34 & 3.93 & 2.80 & 0.416 & 29 & 0.680 \\
\hline RT (ms) - incongruent & 964.03 & 139.58 & 911.20 & 160.28 & 1.467 & 29 & 0.113 \\
\hline RT (ms) - congruent & 901.23 & 195.80 & 821.53 & $|48.7|$ & 2.283 & 29 & 0.030 \\
\hline
\end{tabular}

SV: search velocity; VI: vigilance; RT: reaction time.

Difference is significant at $p<0.05$ level.

Table 4. Spearman's rho correlations between the performance and ocular variables in EV-high condition.

\begin{tabular}{|c|c|c|c|c|c|c|c|c|}
\hline \multirow[b]{3}{*}{ Performance variables } & \multicolumn{8}{|c|}{ Ocular variables } \\
\hline & \multicolumn{2}{|l|}{$\mathrm{BR}$} & \multicolumn{2}{|l|}{ BD } & \multicolumn{2}{|c|}{ PERCLOS } & \multicolumn{2}{|l|}{$\mathrm{EAR}_{\max }$} \\
\hline & $r$ & $p$ & $r$ & $p$ & $r$ & $p$ & $r$ & $p$ \\
\hline Search velocity (SV) & -0.229 & 0.223 & 0.361 & 0.050 & -0.179 & 0.343 & -0.362 & 0.049 \\
\hline Vigilance (VI) & -0.279 & 0.135 & 0.213 & 0.259 & -0.164 & 0.387 & -0.122 & 0.522 \\
\hline Reaction time (RT) - congruent & 0.145 & 0.446 & -0.123 & 0.516 & 0.104 & 0.583 & 0.148 & 0.435 \\
\hline Reaction time (RT) - incongruent & 0.063 & 0.743 & -0.185 & 0.329 & -0.015 & 0.939 & 0.230 & 0.222 \\
\hline
\end{tabular}

BR: blink rate; $B D$ : blink duration; PERCLOS: percentage of eye closure; $E_{A R}$ max: eye aspect ratio-max.

Differences are significant at $p<0.05$ level.

Table 5. Spearman's rho correlation coefficients $(r)$ and $p$ values for the performance and ocular variables in $E_{\vee}$ low condition.

\begin{tabular}{|c|c|c|c|c|c|c|c|c|}
\hline \multirow[b]{3}{*}{ Performance variables } & \multicolumn{8}{|c|}{ Ocular variables } \\
\hline & \multicolumn{2}{|l|}{ BR } & \multicolumn{2}{|l|}{ BD } & \multicolumn{2}{|c|}{ PERCLOS } & \multicolumn{2}{|l|}{$\mathrm{EAR}_{\max }$} \\
\hline & $r$ & $p$ & $r$ & $p$ & $r$ & $p$ & $r$ & $p$ \\
\hline Search velocity (SV) & -0.065 & 0.734 & 0.256 & 0.173 & $-0.07 \mid$ & 0.709 & -0.314 & 0.091 \\
\hline Vigilance $(\mathrm{VI})$ & -0.203 & 0.283 & -0.052 & 0.784 & -0.176 & 0.352 & -0.051 & 0.789 \\
\hline Reaction time (RT) - congruent & 0.366 & 0.047 & -0.234 & 0.214 & 0.368 & 0.045 & 0.068 & 0.721 \\
\hline Reaction time (RT) - incongruent & 0.374 & 0.042 & -0.138 & 0.466 & 0.368 & 0.046 & 0.107 & 0.573 \\
\hline
\end{tabular}

BR: blink rate; BD: blink duration; PERCLOS: percentage of eye closure; EAR $_{\max }$ : eye aspect ratio-max.

Differences are significant at $p<0.05$ level.

vigilance test $(r=0.334, p=0.009)$. RT in sustained attention test when stimuli were congruent was also significantly correlated with the concentration $(r=0.303, p=0.019)$ and mental effort $(r=0.339, p=0.008)$, see Table 6 .
The relationships between objective performance indicators, GSV and KSS

SV was found to be significantly correlated with the GSV $(r=-0.258, p=0.047)$ and more 
Table 6. Spearman's rho correlation coefficients $(r)$ and $p$ values between subjective and objective performance variables.

\begin{tabular}{|c|c|c|c|c|c|c|c|c|}
\hline \multirow[b]{2}{*}{ Performance variables } & \multicolumn{2}{|c|}{ Overall success } & \multicolumn{2}{|c|}{ Motivation } & \multicolumn{2}{|c|}{ Concentration } & \multicolumn{2}{|c|}{ Mental effort } \\
\hline & $r$ & $p$ & $r$ & $p$ & $r$ & $p$ & $r$ & $p$ \\
\hline SV - search velocity & -0.235 & 0.070 & -0.133 & 0.312 & 0.232 & 0.074 & 0.148 & 0.260 \\
\hline ER - total errors & -0.150 & 0.252 & -0.104 & 0.428 & -0.067 & 0.609 & 0.334 & 0.009 \\
\hline RT - congruent & -0.243 & 0.061 & 0.016 & 0.901 & 0.303 & 0.019 & 0.339 & 0.008 \\
\hline RT - incongruent & -0.241 & 0.064 & -0.129 & 0.326 & 0.010 & 0.942 & 0.039 & 0.767 \\
\hline
\end{tabular}

Differences are significant at $p<0.05$ level.

Table 7. Spearman's correlation coefficients between cognitive performance, GSV and KSS.

\begin{tabular}{|c|c|c|c|c|}
\hline \multirow[b]{2}{*}{ Performance variables } & \multicolumn{2}{|l|}{ GSV } & \multicolumn{2}{|l|}{$\mathrm{KSS}_{\mathrm{avg}}$} \\
\hline & $r$ & $p$ & $r$ & $p$ \\
\hline SV - search velocity & -0.258 & 0.047 & 0.375 & 0.003 \\
\hline ER - total errors & -0.047 & 0.722 & -0.097 & 0.461 \\
\hline RT - congruent & 0.087 & 0.507 & 0.224 & 0.085 \\
\hline RT - incongruent & 0.191 & 0.143 & 0.271 & 0.036 \\
\hline
\end{tabular}

GSV: glare sensation vote; KSS: Karolinska Sleepiness Scale. Differences are significant at $p<0.05$ level.

pronouncedly with the KSS ratings $(r=0.375$, $p=0.003)$. Also, a statistically significant positive correlation was found between the KSS score and the RT in sustained attention test when the stimuli were incongruent $(r=0.271$, $p=0.036)$, see Table 7 .

\section{The relationships between ocular parameters and STP, GSV and KSS}

$\mathrm{EAR}_{\max }$ showed significant positive correlations with the self-rated overall scores in letter search test $(r=0.501 ; p=0.00)$ and in vigilance test $(r=0.467 ; p=0.00)$. A significant correlation was also found between self-rated motivation score and $\mathrm{EAR}_{\max }$ during letter search test $(r=0.405 ; p=0.001)$. Moreover, self-reported concentration in vigilance test was found to be significantly correlated with $\mathrm{EAR}_{\max }(r=0.465$; $p=0.00)$. The level of perceived glare was significantly correlated with $\mathrm{BD}(r=-0.278$; $p=0.031)$ and $\mathrm{EAR}_{\max }(r=0.263 ; p=0.043)$. Finally, the relationship between $\mathrm{KSS}_{\mathrm{avg}}$ and PERCLOS was found to be statistically significant $(r=0.259 ; p=0.046)$. More detailed information on each relationship was presented in Table 8.

\section{Discussion}

Firstly, variables were tested under the impact of two daylighting design scenarios, when shadings are active ( $\mathrm{E}_{\mathrm{V}}$-low) and inactive ( $\mathrm{E}_{\mathrm{V}}$-high). Results regarding the physiological variables showed that some of the ocular measures were highly sensitive to illuminance (see Table 2). For example, significant effects of illuminance were found on $\mathrm{EAR}_{\max }$ in all tests, revealing lower $\mathrm{EAR}_{\max }$ as illuminance increases which might be a good news for future research to be utilized as a reliable ocular clue while analysing physiological changes during VDT use. Concerning PERCLOS, we found controversial PERCLOS results among tests ranging from $3 \%$ to $30 \%$ roughly. This result might be due to the different cognitive functions required in each test, and is indeed similar to what has been reported in previous research wherein PERCLOS values were ranging from $7.5 \%$ to $80 \%{ }^{59,60}$ This, in fact, gives a good representation of PERCLOS being dependent on the different levels of cognitive demands. Another thought-provoking finding was that lower PERCLOS values were found under the influence of low levels of 
Table 8. Correlations between ocular variables and self-reported performance, glare sensation and alertness answers.

\begin{tabular}{|c|c|c|c|c|c|c|c|c|}
\hline \multirow[b]{2}{*}{ Test types } & \multicolumn{2}{|l|}{$\mathrm{BR}$} & \multicolumn{2}{|l|}{$\mathrm{BD}$} & \multicolumn{2}{|c|}{ PERCLOS } & \multicolumn{2}{|l|}{$\mathrm{EAR}_{\max }$} \\
\hline & $r$ & $p$ & $r$ & $p$ & $r$ & $p$ & $r$ & $p$ \\
\hline Overall success - letter search test & -0.013 & 0.919 & -0.231 & 0.076 & -0.038 & 0.774 & 0.501 & 0.00 \\
\hline Overall success - vigilance test & -0.030 & 0.821 & 0.151 & 0.251 & -0.021 & 0.875 & 0.467 & 0.00 \\
\hline Overall success - Stroop test & -0.099 & 0.451 & -0.016 & 0.904 & -0.014 & 0.913 & $0.17 \mid$ & 0.191 \\
\hline Motivation - letter search test & 0.035 & 0.788 & -0.084 & 0.525 & 0.002 & 0.989 & 0.405 & 0.001 \\
\hline Motivation - vigilance test & 0.224 & 0.085 & -0.020 & 0.879 & 0.206 & 0.115 & $0.14 \mid$ & 0.284 \\
\hline Motivation - Stroop test & -0.152 & 0.246 & -0.101 & $0.44 I$ & -0.129 & 0.326 & 0.127 & 0.333 \\
\hline Concentration - letter search test & -0.133 & 0.310 & 0.187 & 0.153 & -0.117 & 0.375 & -0.229 & 0.079 \\
\hline Concentration - vigilance test & 0.254 & 0.050 & -0.115 & 0.381 & 0.296 & 0.022 & 0.465 & 0.00 \\
\hline Concentration - Stroop test & 0.191 & 0.143 & 0.222 & 0.089 & 0.242 & 0.062 & -0.033 & 0.804 \\
\hline Mental effort - letter search test & -0.032 & 0.808 & 0.222 & 0.089 & -0.006 & 0.961 & -0.118 & 0.368 \\
\hline Mental effort - vigilance test & -0.049 & $0.7 I I$ & 0.130 & 0.323 & 0.072 & 0.583 & 0.076 & 0.566 \\
\hline Mental effort - Stroop test & 0.017 & 0.899 & 0.140 & 0.285 & 0.105 & 0.422 & 0.166 & 0.206 \\
\hline GSV & 0.245 & 0.059 & -0.278 & 0.031 & 0.189 & 0.149 & -0.263 & 0.043 \\
\hline $\mathrm{KSS}_{\text {avg }}$ & 0.224 & 0.085 & 0.172 & 0.190 & 0.259 & 0.046 & -0.199 & 0.127 \\
\hline
\end{tabular}

BR: blink rate; BD: blink duration; GSV: glare sensation vote; KSS: Karolinska Sleepiness Scale; PERCLOS: percentage of eye closure; $\mathrm{EAR}_{\text {max }}$ : eye aspect ratio-max.

Differences are significant at $p<0.05$ and $p<0.0$ l levels.

vertical illuminance during vigilance test, whereas an opposite trend was observed during the test requiring sustained attention. This might be due to differences in the cognitive functions in response to different lighting settings. Concerning BD, only significant difference was found during Stroop test, which may not be enough to draw a generalizable conclusion for being utilized as a physiological metric. Finally, no significant effect of illuminance was found on BR, which is also supported by earlier studies suggesting that BR can be determined by many factors which makes it open to contamination, and thus is less often used as an ocular parameter in this field of research. ${ }^{61-63}$

Regarding performance measures, the current results revealed that lower illuminances improved the cognitive performance on a test requiring sustained attention, while no significant effects were observed on tests including such cognitive functions as SV and vigilance (see Table 3). This might be because the daylit work environment has a much slighter influence on SV and vigilance than on the performance of a sustained-attention requiring test, and is also in line with the findings obtained from our previous study. ${ }^{38}$

Secondly, the relationships between ocular and performance variables were analysed separately in $\mathrm{E}_{\mathrm{V}}$-low and $\mathrm{E}_{\mathrm{V}}$-high scenarios. In $\mathrm{E}_{\mathrm{V}}$-high condition, results revealed that only SV was significantly correlated with $\mathrm{BD}$ and $\mathrm{EAR}_{\max }$ (see Table 4). These findings may suggest that $\mathrm{BD}$ and $\mathrm{EAR}_{\max }$ are likely to be used as physiological measures in cognitive tests evaluating $\mathrm{SV}$, in such daylit spaces wherein higher vertical illuminances with an average of $14001 \mathrm{x}$ are predominant. Differently in $\mathrm{E}_{\mathrm{V}}$-low condition, $\mathrm{BR}$ and PERCLOS were significantly correlated with the RT in the sustained attention test when the stimuli were both congruent and incongruent (see Table 5). At this point, the same interpretation can be employed for BR and PERCLOS to be utilized as ocular measures in such tests measuring sustained attention when lower 
illuminances of around $800 \mathrm{~lx}$ are predominant inside the space.

Regarding the subjective performance indicators, participants' self-reported measures on mental effort and concentration were significantly correlated with the time spent in sustained attention test while the stimuli were congruent. Similarly, increase in the mental effort during vigilance test was not able to decrease the errors made. These findings suggest that increased mental effort and concentration during such tests are likely to arise due to the cognitive difficulty levels (see Table 6).

Concerning the relationships between performance variables and the GSV and KSS ratings, SV was found highly correlated with the KSS, revealing that the prolonged search time is coherent with higher KSS scores that signifies less arousal (see Table 7). The same relationship was also found between RT and KSS scores in Stroop test, which implies that affective state might be considered as a useful clue for measuring cognitive functions. Finally, a correlation in unpredicted direction was found between GSV ratings and SV, indicating a relationship between prolonged $\mathrm{SV}$ and less sensation of glare which requires a follow-up investigation.

As for the relationships between ocular and STP variables, the results revealed that $\mathrm{EAR}_{\text {max }}$ showed the highest number of correlations with the STP items, whereas BD and PERCLOS showed weaker relationship with only a few items, and BR was not found to be significantly correlated with any STP items (see Table 8).

Considering the GSV ratings, the results showed a significant negative correlation between GSV and $\mathrm{EAR}_{\max }$ (see Table 8). This suggests that subjective disturbance of glare can be associated with reduced eye openness during performing such cognitive tests. In further studies with a wider range of subjects, the robustness of the use of $\mathrm{EAR}_{\max }$ needs to be enhanced for its implementation as a metric for identifying the physiological and affective changes in VDT workers under various lighting conditions. Regarding another negative correlation between GSV and BD, one possible explanation might be that shorter BD is in fact related to the subjective feeling of visual disturbance that forces an individual to blink faster than usual, though previous studies generally associate prolonged eye closure with higher load, visual demand or less arousal. As for the relationship between KSS and the ocular variables, higher PERCLOS was found to be significantly correlated with less arousal, thus confirming earlier studies suggesting this metric for measuring the level of alertness.

\section{Future research directions}

In this study, we investigated the impacts of varying levels of illuminance by comparing two fixed façade settings. A next step could be allowing users to manipulate the shading as they prefer, to investigate whether any performance differences will be found under default and preferred lighting settings. Moreover, this study was undertaken in a workplace setting in which the user was sitting and facing parallel to the window; but it is not highly recommended due to the possibility of glare. To find out the magnitude of the layout impacts on cognitive load, this study should be replicated in a workplace setting that is recommended by the guidelines. Artificial light is another significant aspect, since there is often an integration between daylight and electrical light in workplaces. We should further investigate the cognitive load of VDT users under this sort of lighting setting to test whether there will be any positive cognitive, affective and physiological changes with the contribution of artificial light.

\section{Conclusion}

Most research published in this field so far have used different experimental methods for determining cognitive load under the influence of luminous environment. They individually serve to bring a deeper knowledge for better understanding of such clues on lighting of workspaces as to predict cognitive processes during VDT use. On the other hand, the whole picture 
requires more multi-directional experimental designs also considering the fact that in reality, various tasks are performed in such VDT workspaces wherein mainly dynamic daylighting conditions are dominant. For this reason, cognitive load of VDT workers needs to be analysed under more sensitive experimental lighting conditions. This should be implemented with such an approach not only by means of comparisons of specific assessment factors (e.g. performance, subjective, physiological measures) under different lighting scenarios but also relating these measures to one another. This will ultimately help to alleviate health, wellbeing and performance related problems in workspaces and contribute to organizational productivity.

The aim of the present study, accordingly, was to analyse cognitive load of VDT workers with a multi-perspective approach based on three groups of variables (performance, physiological, subjective) while various computerbased tests were being performed in a full-scale mock-up daylit VDT workstation.

The findings of this study could suggest that a practical application, the use of a shading device, might deliver an efficient solution on such a multifaceted question about the potential effects of luminous environment on the evaluation of cognitive load. Work environments might be considered as cognitively efficient if only the harmony of less mental effort, more satisfaction and less health problems exist, which together ultimately deliver higher work performance. In real-world work environments, application of such shading devices involves advantages not for only avoiding excessive daylight exposure or optimizing energy consumption, but also facilitating cognitive, affective and physiological processes of individuals.

\section{Authors' contribution}

All authors contributed equally in the preparation of this manuscript.

\section{Declaration of conflicting interests}

The author(s) declared no potential conflicts of interest with respect to the research, authorship, and/or publication of this article.

\section{Funding}

The author(s) received no financial support for the research, authorship, and/or publication of this article.

\section{ORCID iDs}

M Öner (D) https://orcid.org/0000-0001-5551-068X

G Salvadori (D) https://orcid.org/0000-0002-0720-2380

\section{References}

1. Leccese F, Salvadori G and Rocca M. Visual ergonomics of video-display-terminal workstations: field measurements of luminance for various display settings. Displays 2016; 42: 9-18.

2. Leccese F, Salvadori G and Rocca M. Visual discomfort among university students who use CAD workstations. WORK J Prev Assess Rehabil 2016; 55: 171-180.

3. Göçer Ö, Göçer K, Ergöz Karahan E, et al. Exploring mobility \& workplace choice in a flexible office through post-occupancy evaluation. Ergonomics 2018; 61: 226-242.

4. Boyce P, Hunter C and Howlett, O. The benefits of daylight through windows. Troy, NY: Lighting Research Center, 2003.

5. Paas F and Van Merriënboer JJG. Instructional control of cognitive load in the training of complex cognitive tasks. Educ Psychol Rev 1994; 6: 351-371.

6. Choi HH, Van Merriënboer JJG and Paas FGWC. Effects of the physical environment on cognitive load and learning: towards a new model of cognitive load. Educ Psychol Rev 2014; 26: 225-244.

7. Brünken R, Seufert T and Paas FGWC. Measuring cognitive load. In: Sweller J, Ayres P and Kalyuga S (eds) Cognitive load theory. New York, NY: Springer, 2011, pp. 71-85.

8. Hart SG and Staveland L. Development of the NASA task load index (TLX): results of empirical and theoretical research. In: Meshkati N (ed.) Human mental workload. Amsterdam: North-Holland, 1988, pp.39-183.

9. Örün Ö and Akbulut Y. Effect of multitasking, physical environment and electroencephalography use on cognitive load and retention. Comput Hum Behav 2019; 92: 216-229.

10. Miyake S. Multivariate workload evaluation combining physiological and subjective measures. Int $J$ Psychophysiol 2001; 40: 233-238. 
11. Just MA, Carpenter PA and Miyake A. Neuroindices of cognitive workload: neuroimaging, pupillometric and event-related potential studies of brain work. Theor Issues Ergon Sci 2003; 4: 56-88.

12. Xu J, Wang Y, Chen F, et al. Pupillary response based cognitive workload measurement under luminance changes. Hum-Comput Interact 2011: 178-185.

13. Martins $\mathrm{R}$ and Carvalho J. Eye blinking as an indicator of fatigue and mental load - a systematic review. In: Arezes PM, Baptista JS, Barroso MP, et al. (eds) Occupational safety and hygiene III. London: CRC Press, 2015, pp.231-235.

14. Mayer RE. Multimedia learning. 2nd ed. New York, NY: Cambridge University Press, 2009.

15. Marcus N, Cooper M and Sweller J. Understanding instructions. J Educ Psychol 1996; 88: 49-63.

16. Waters GS and Caplan D. Verbal working memory and on-line syntactic processing: evidence from self-paced listening. $Q J$ Exp Psychol 2004; 57: 129-163.

17. Van Der Linden D, Frese M and Meijman, TF. Mental fatigue and the control of cognitive processes: effects on perseveration and planning. Acta Psychol 2003; 113: 45-65.

18. Knez I. Effects of indoor lighting on mood and cognition. J Environ Psychol 1995; 15: 39-51.

19. Hygge $\mathrm{S}$ and Knez I. Effects of noise, heat and indoor lighting on cognitive performance and self-reported affect. J Environ Psychol 2001; 21: 291-299.

20. Sun C, Lian Z and Lan L. Work performance in relation to lighting environment in office buildings. Indoor Built Environ. Epub ahead of print 26 December 2018. https:// doi.org/10.1177/1420326X18820089

21. Smolders KCHJ, De Kort YAV and Cluitmans PJM. A higher illuminance induces alertness even during office hours: findings on subjective measures, task performance and heart rate measures. Physiol Behav 2012; 107: 7-16.

22. Eklund NH, Boyce PR and Simpson SN. Lighting and sustained performance. J Illum Eng Soc 2000; 29: 116-130.

23. Fostervold K and Nersveen J. Proportions of direct and indirect indoor lighting - the effect on health, well-being and cognitive performance of office workers. Light Res Technol 2008; 40: 175-200.

24. Hawes BK, Brunyé TT, Mahoney CR, et al. Effects of four workplace lighting technologies on perception, cognition and affective state. Int $J$ Ind Ergon 2012; 42: 122-128.

25. Ferlazzo F, Piccardi L, Burattini C, et al. Effects of new light sources on task switching and mental rotation performance. J Environ Psychol 2014; 39: 92-100.

26. Knez I and Hygge S. Irrelevant speech and indoor lighting: effects on cognitive performance and self-reported affect. Appl Cognit Psychol 2002; 16: 709-718.
27. Yamin Garretón JA, Rodriguez RG, Ruiz A, et al. Degree of eye opening: a new discomfort glare indicator. Build Environ 2015; 88: 142-150.

28. Yamin Garretón JA, Rodriguez RG and Pattini AE. Glare indicators: an analysis of ocular behaviour in an office equipped with venetian blinds. Indoor Built Environ 2016; 25: 69-80.

29. Cuttle C. People and windows in workplaces. In: Proceedings of the people and physical environment research conference, Wellington, New Zealand, 8-11 June 1983, pp.203-212.

30. Veitch JA and Gifford R. Assessing beliefs about lighting effects on health, performance, mood and social behavior. Environ Behav 1996; 28: 446-470.

31. Veitch JA, Hine DW and Gifford R. End users' knowledge, preferences, and beliefs for lighting. J Inter Des 1993; 19: 15-26.

32. Heerwagen JH and Heerwagen DR. Lighting and psychological comfort. Light Des Appl 1986; 16: 47-51.

33. Kunduraci AC, Kazanasmaz $\mathrm{T}$ and Hordijk $\mathrm{T}$. Examining occupancy and architectural aspects affecting manual lighting control behaviour in offices based on a user survey. Light Eng 2018; 26: 139-147.

34. Leccese F, Salvadori G, Montagnani C, et al. Lighting assessment of ergonomic workstation for radio diagnostic reporting. Int J Ind Ergon 2017; 57: 42-54.

35. Roenneberg T, Wirz-Justice A and Merrow M. Life between clocks: daily temporal patterns of human chronotypes. J Biol Rhythms 2003; 18: 80-90.

36. Fortuin G. Visual power and visibility. Philips Res Rep 1951; 6: 347-371.

37. Occupational Safety and Health Administration. Indoor air quality investigation, 1999, https://www.osha.gov/ dts/osta/otm/otm_iii/otm_iii_2.html\#5 (accessed 18 June 2019).

38. Leccese F, Salvadori G, Öner M, et al. Exploring the impact of external shading system on cognitive task performance, alertness and visual comfort in a daylit workplace environment. Indoor Built Environ. Epub ahead of print 2019. https://doi.org/10.1177/1420326X19864414

39. Van Rossum G and Drake FL. Python Language reference manual. Bristol: Network Theory Ltd, 2011.

40. Soukupová T and Cech J. Real-time eye blink detection using facial landmarks. In: Proceedings of the 21st computer vision winter workshop, Rimske Toplice, Slovenia, 3-5 February 2016.

41. Wienold J. Daylight glare in offices. Doctoral dissertation, Universität Karlsruhe (TH), Germany, 2009.

42. Stoet G. PsyToolkit - a software package for programming psychological experiments using Linux. Behav Res Methods 2010; 42: 1096-1104.

43. Stoet G. PsyToolkit: a novel web-based method for running online questionnaires and reaction-time experiments. Teach Psychol 2017; 44: 24-31. 
44. Lichstein KL, Riedel BW and Richman SL. The Mackworth clock test: a computerized version. J Psychol 2000; 134: 153-161.

45. Mackworth NH. The breakdown of vigilance during prolonged visual search. $Q J$ Exp Psychol 1948; 1: 6-21.

46. Bruneau D, Sasse MA and McCarthy JD. The eyes never lie: the use of eye tracking data in HCI research. In: Proceedings of the CHI'02 workshop on physiological computing, New York, NY: ACM Press, 2002.

47. Sheedy JE and Shaw-McMinn PG. Diagnosing and treating computer-related vision problems. Woburn, MA: Butterworth-Heinemann, 2002.

48. Sheedy JE, Smith R and Hayes J. Visual effects of the luminance surrounding a computer display. Ergonomics 2005; 48: 1114-1128.

49. Nie B, Huang X, Chen Y, et al. Experimental study on visual detection for fatigue of fixed-position staff. Appl Ergon 2017; 65: 1-11.

50. Benedetto S, Pedrotti M, Minin L, et al. Driver workload and eye blink duration. Transport Res F 2011; 14: 199-208.

51. McIntire LK, McKinley RA, Goodyear C, et al. Detection of vigilance performance using eye blinks. Appl Ergon 2014; 45: 354-362.

52. Wierwille WW and Eggemeier FT. Recommendations for mental workload measurement in a test and evaluation environment. Hum Factors 1993; 35: 263-281.

53. Rezaei M and Klette R. Computer vision for driver assistance: simultaneous traffic and driver monitoring. Berlin: Springer, 2017.

54. Kawashima R, O'Sullivan BT and Roland PE. Positron-emission tomography studies of crossmodality inhibition in selective attentional tasks: closing the "mind's eye". Proc Natl Acad Sci U S A 1995; 92: 5969-5972.

55. Marshall SP. Identifying cognitive state from eye metrics. Aviation Space Environ Med 2007; 78: B165-B175.

56. Åkerstedt T and Gillberg M. Subjective and objective sleepiness in the active individual. Int J Neurosci 1990; 52: 29-37.

57. Hopkinson RG. The multiple criterion technique of subjective appraisal. $Q J$ Exp Psychol 1950; 2: 124-131.

58. Huiberts LM, Smolders KCHJ and de Kort YAW. Shining light on memory: effects of bright light on working memory performance. Behav Brain Res 2015; 294 : 234-245.

59. Papadelis C, Chen Z, Kourtidou-Papadeli C, et al. Monitoring sleepiness with on-board electrophysiological recordings for preventing sleep-deprived traffic accidents. Clin. Neurophysiol 2007; 118: 1906-1922.

60. Jo J, Lee SJ, Park KR, et al. Detecting driver drowsiness using feature-level fusion and user-specific classification. Expert Syst Appl 2014; 41: 1139-1152.

61. Goldberg HJ and Wichansky AM. Eye tracking in usability evaluation: a practitioner's guide. In: J Hyönä, R Radach and H Deubel (eds) The mind's eye: cognitive and applied aspects of eye movement research. Amsterdam: Elsevier, 2003, pp.493-516.

62. Poole A and Ball LA. Eye tracking in human-computer interaction and usability research: current status and future prospects. In: Ghaoui C (ed.) Encyclopedia of human-computer interaction. Hershey, PA: Idea Group Inc, 2005, pp.211-219.

63. Cornish L, Hill A, Horswill MS, et al. Eye-tracking reveals how observation chart design features affect the detection of patient deterioration: an experimental study. Appl Ergon 2019; 75: 230-242. 